Original Research Paper

\title{
Modeling, Simulation and Optimization of Steel Sandwich Panels under Blast Loading
}

\author{
${ }^{1}$ Sayed M. Soleimani, ${ }^{2}$ Nader H. Ghareeb and ${ }^{1}$ Nourhan H. Shaker \\ ${ }^{1}$ Department of Civil Engineering, Australian College of Kuwait, Kuwait \\ ${ }^{2}$ Department of Mechanical Engineering, Australian College of Kuwait, Kuwait
}

\author{
Article history \\ Received: 07-06-2018 \\ Revised: $13-07-2018$ \\ Accepted: 04-08-2018 \\ Corresponding Author: \\ Sayed M. Soleimani \\ Department of Civil \\ Engineering, Australian \\ College of Kuwait, Kuwait \\ Email: s.soleimani@ack.edu.kw
}

\begin{abstract}
Honeycomb sandwich panels are commonly preferred in structural engineering as a design element meant to protect against blast loading, and this owes primarily to the fact that they are light in weight (due to the voids present) whilst carrying high energy absorption capacities. A widespread surge in acts of terrorism, and the resultant threat posed to structures, presents structural engineers with unique challenges pertaining to the design of blast-resistant structures that are both safe and reliable. Researchers worldwide have thus taken to closely studying the effects of sudden loads effected by detonative forces on certain elements and design concepts. To this end, an emergent design concept with proven efficacy is the honeycomb sandwich panel. Due to the practical difficulties associated with the study of explosive materials and replicating blast loads, softwarebased modeling and simulation may be favorable as a functional and convenient alternative. To this end, this work uses the finite element package ABAQUS ${ }^{\circledR}$ to study the behavior of hexagonal and squared honeycomb steel sandwich panels under the explosive effects of different amounts of trinitrotoluene (TNT). The results of finite element modeling of a specific honeycomb configuration are initially validated by comparing them with the experimental results from literature. Several configurations including different geometrical properties of the honeycomb wall are then investigated and the results are compared. Consequently, an optimization study is conducted with an objective to reduce the plastic strain of the back plate while the wall cell thickness is taken as a variable. Finally, the effectiveness of the core shape and wall thickness is discussed and conclusions are made.
\end{abstract}

Keywords: Blast Loading, Finite Element Modeling, Steel Honeycomb Sandwich Panels, Optimization

\section{Introduction}

Terrorist attacks against important structures such as bombing of the marine barracks in Beirut in 1983, the Khobar Towers in Saudi Arabia in 1996, the U.S. embassies in Nairobi in 1998 and Dar El-Salaam in 1998 and the governmental building in Oslo in 2011 have increased over the past decades. Such brutal activities alarmed structural engineers to develop methods of design and analysis to protect citizens and properties against blast loads. In this study, honeycomb sandwich panels act as energy absorbers from the blast. Studying explosion effects on the panels require experimental work known to be costly and time consuming. Moreover, these kinds of explosive based experiments are not easy to implement and permissions from defense organizations are necessary. The other alternative, using a simulation program, is preferable compared to experimental works due to its lower cost and time consumption.

Additionally, reducing the mass of the structure while maintaining the same level of resistance against blast loading has always been considered as a challenging problem. Monolithic structures are getting replaced by honeycomb sandwich panels due to their light weight, high stiffness and strength, and durability. Researchers are focusing on studying the effectiveness of sandwich panels for absorbing the energy and managing the 
impulse associated with blast loading. They have expanded their research into optimizing the core size and the wall thickness to maximize the blast energy absorption capacity while maintaining reasonable deflections of the panel. Zhu and Lu (2007) studied the characteristics of blast loads and its corresponding structural response and concluded that structures affected by blast waves can undergo large inelastic deformation, tearing, or transverse shear failure at the support. Soleimani et al. (2006) and Yuen et al. (2009) studied the modeling and simulation of honeycomb steel sandwich panels under blast loading. Xue and Hutchinson (2005) focused more on studying the effectiveness of square honeycomb sandwich cores in absorbing blast waves using a continuum model software. Square-core sandwich panels showed high energy absorption and crushing strength. Fleck and Deshpande (2004) analyzed the blast resistance of clamped sandwich beams. Experimental tests were conducted by Dharmasena et al. (2008) to study the dynamic mechanical response of square honeycomb core sandwich panels. They have shown that the square honeycomb panels are capable of withstanding air blast loads. Nayak et al. (2012) presented a method of optimizing sandwich panels so as to minimize the effects of air blast loading. The sandwich panel consisted of two metal face plates with a crushable honeycomb core. In their study, a Design Of Experiments (DOE) based response surface optimization method was used in combination with LS-DYNA to mitigate instances of dynamic deflection or acceleration of the back-face plate.

Since the previous research work in this area has not covered the optimization of the cell structure and the comparison between hexagonal and squared cores, this research is focused on these two matters. In this study, the Finite Element Method (FEM) package ABAQUS ${ }^{\circledR}$ is adopted to model steel square and hexagonal honeycomb sandwich panels with different cell wall thicknesses. Five core sizes with varying cell wall thickness are then modeled and simulated to investigate their effects on the final deflection of the sandwich panel. The optimization software ISIGHT $^{\circledR}$ is used to optimize the wall thickness of a specific core size for both square and hexagonal core shapes. The dimensions of the sandwich panels are chosen to be similar to those studied by Dharmasena et al. (2008).

\section{The Blast Load}

An explosion by definition is a large-scale, rapid and sudden release of energy. Explosives can be classified according to their sensitivities to ignition and may be referred to as either primary or secondary explosives. Among these, primary explosives are the ones that can be easily detonated by a simple ignition from a spark, flame or any form of impact. Mercury fulminate and lead azide are such primary explosive materials. On the other hand, secondary explosives are the ones that when detonated, create blast (shock waves), causing widespread damage to the surroundings. TNT and Ammonium Nitrate Fuel Oil (ANFO) are examples of secondary explosives. Condensed high explosives generate hot gases under pressure up to $300 \mathrm{kbar}$, with temperatures of about $3000-4000^{\circ} \mathrm{C}$. This hot gas then expands, forcing out the volume it occupies. The blast wave increases to a value of pressure much above the ambient atmospheric pressure. It is referred to as the side-on overpressure which decays as the shock wave goes further away from the explosion center. This pressure behind the front will drop below the ambient pressure within a short time and create a negative phase, which is basically a partial vacuum, as air is sucked in. This effect is accompanied by high suction winds that blow debris far away from the explosion source.

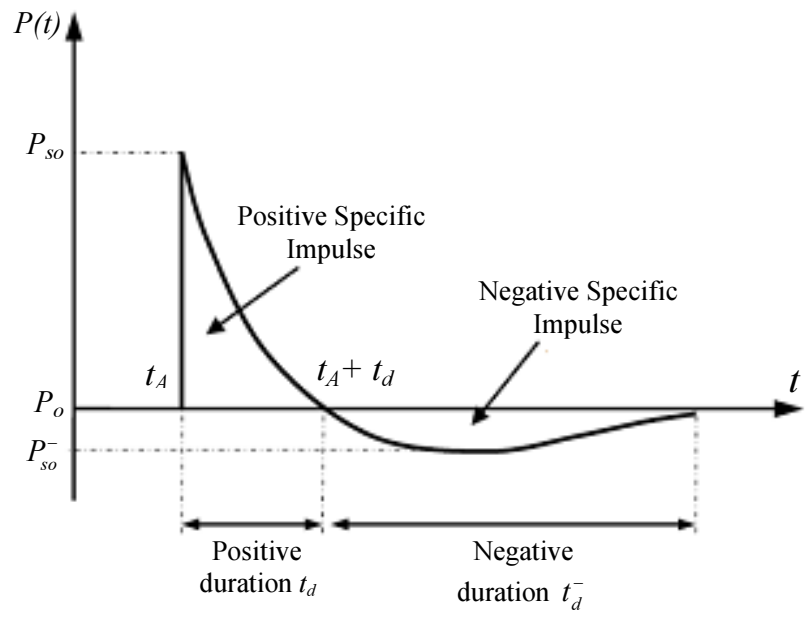

Fig. 1: Time history of blast wave pressure (Dharmasena et al., 2008) 
The threat of a bomb can be defined by two elements, both being equally important. The first is the bomb size, or the charge weight $\mathrm{W}$, while the second is the standoff distance $\mathrm{R}$ between the blast source and the target. Figure 1 shows a typical blast pressure profile.

At the blast arrival time $t_{A}$, after the explosion, there is a sudden increase in pressure, leading to the formation of a peak value of overpressure $P_{s o}$, over the ambient pressure $P_{o}$. The pressure then decays suddenly to ambient level after duration $t_{d}$, then decays further to an under pressure $P_{\text {so }}{ }^{-}$(creating a partial vacuum) before finally returning to ambient conditions at time $t_{A}+t_{d}+t_{d}^{-}$.

\section{Sandwich Panel Configuration}

Dharmasena et al. (2008) used square honeycomb sandwich panels in their experimental work. All panels were subjected to large bending loads at the center. Through welding of the core webs and face sheets, a large contact area was achieved, creating high strength joints. Xue and Hutchinson (2005) have shown that sandwich core relative densities in the 3$10 \%$ range are of most interest for blast resisting structures. To this end, all square honeycomb core panels were designed and fabricated to achieve a core with a relative density of approximately $6 \%$. They had a thickness of $5 \mathrm{~mm}$ for the front and back plate and $51 \mathrm{~mm}$ for the core. The square core is formed from $0.76 \mathrm{~mm}$ thick webs and $5 \mathrm{~mm}$ flange width spaced evenly at a distance of $30.5 \mathrm{~mm}$. In their experimental work, TNT explosives were used and set $100 \mathrm{~mm}$ away from center of the square sandwich panel with mass charges of 1,2 and $3 \mathrm{~kg}$.

The material used to create the sandwich structure was high ductility stainless steel alloy (AL6XN) composed of $49 \% \mathrm{Fe}, 24 \% \mathrm{Ni}, 21 \% \mathrm{Cr}$ and $6 \%$ Mo by weight. It was modeled as a rate dependent plastic material using the Johnson-Cook model for strain hardening and rate dependency. The values of the constants were: $A=400 \mathrm{MPa}, B=1500 \mathrm{MPa}, C=$ $0.045, n=0.4, m=1.2, \square \square_{o}=0.001 \mathrm{~s}^{-1}, T_{t r}=293 \mathrm{~K}$, $T_{m}=1800 \mathrm{~K}$ and $C_{p}=452 \mathrm{~J} / \mathrm{kg}-\mathrm{K}$. The mechanical properties for the AL6XN were obtained from Nahshon et al. (2007) with $E=161 \mathrm{GPa}, v=0.35$ and $\rho=7850 \mathrm{~kg} / \mathrm{m}^{3}$. The dimensions of the panel used in their experimental study are $610 \times 610 \mathrm{~mm}$ (Fig. 2).

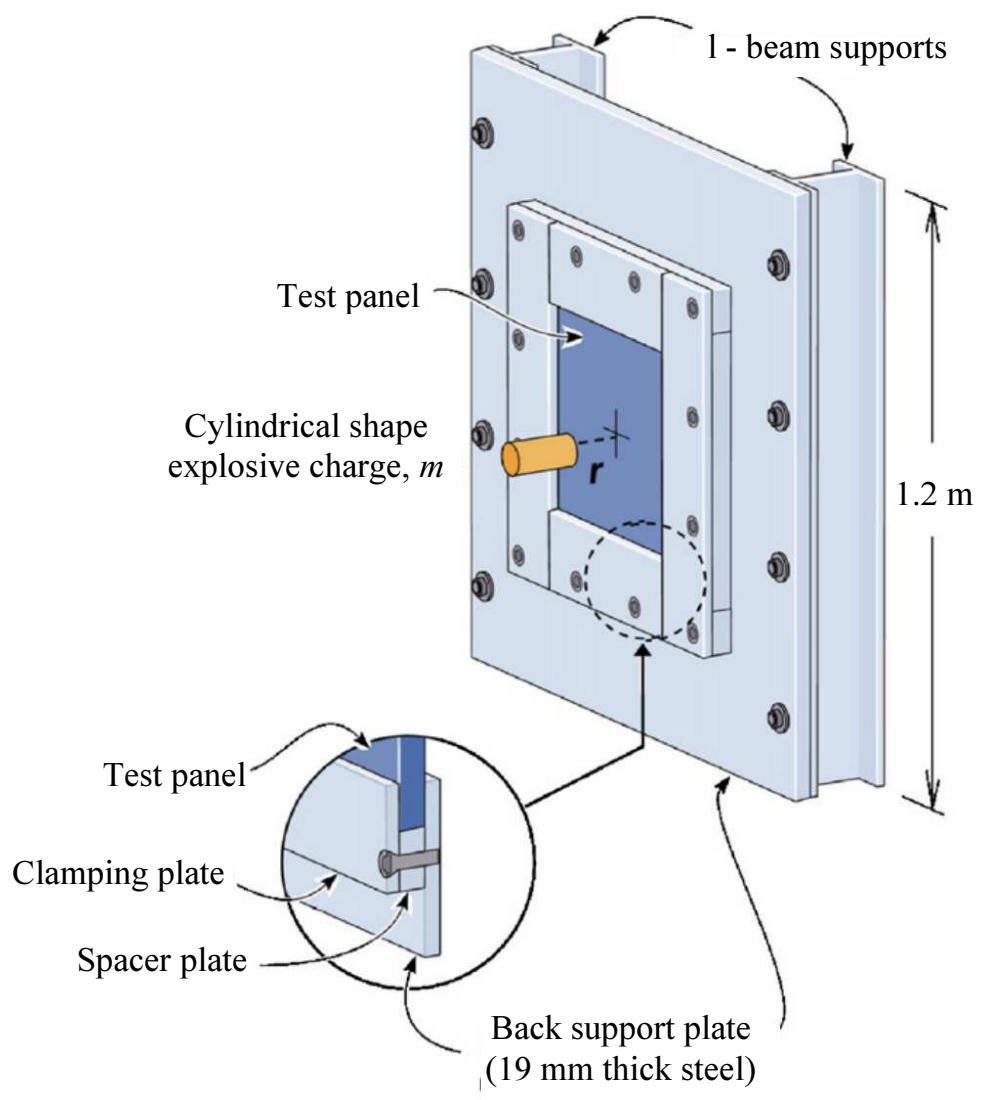

Fig. 2: Schematic arrangement for air blast test (Dharmasena et al., 2008) 


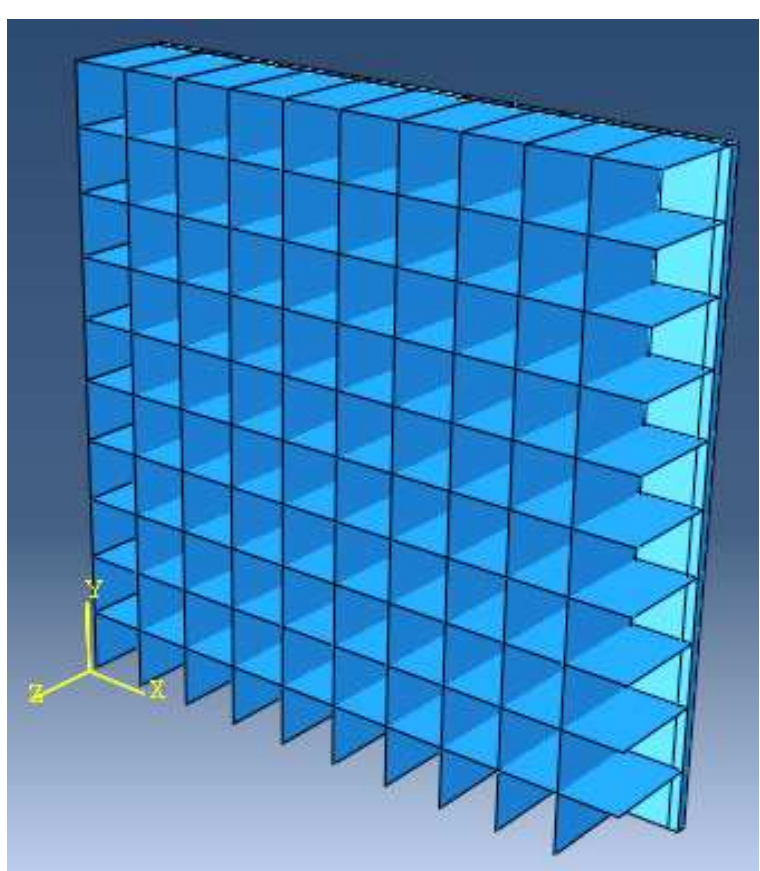

(a)

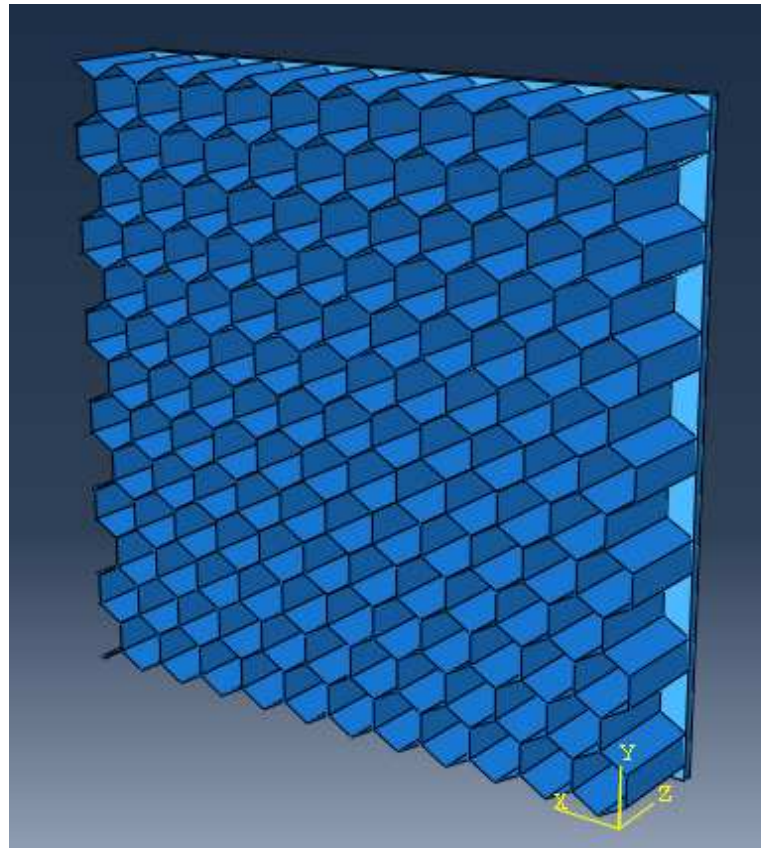

(b)

Fig. 3: FEM model of a honeycomb panel (front plate not shown): (a) square core; (b) hexagonal core

\section{Sandwich Panel Modeling}

In this study, square and hexagonal sandwich panels are modeled. The square ones are similar to those used in the experiment. Due to symmetry conditions, only one quarter of the geometry $(305 \times 305 \mathrm{~mm})$ is modeled (Fig. 3). Both panels are considered to be symmetrical homogenous panels made of isotropic material. The model of honeycomb core was initially created in AutoCAD and then imported into ABAQUS ${ }^{\circledR}$, where the top and bottom plates were added. The nodes at the outer edge (perimeter of the panel) are fixed and the nodes along the symmetrical lines are free to move in the direction perpendicular to the plate surface (z-direction). The conventional explosives were detonated at a fixed distance of $100 \mathrm{~mm}$ from the front plate of the square and hexagonal honeycomb core panels. The charge mass of detonated TNT was 1,2 and $3 \mathrm{~kg}$.

The top and bottom plates were discretized using $31 \times 31 \times 5 \mathrm{~mm}$ Continuum-3D eight-noded solid elements with Reduced integration (C3D8R). The core was discretized using 30 four-noded bilinear shell elements with reduced integration (S4R), along the height of the core. The total number of the nodes for $31 \mathrm{~mm}$ cells in squared and hexagonal configurations is 242 and 672 , respectively.

Overall, the simulations capture major deformations with buckling and significant folding of the inner webs as displayed by the animation of the deformed plate over the entire time period of 1.5 milliseconds (Fig. 4). It shows large deformations at the center and the plate stabilizes after a few oscillations.

\section{Validation of Modeled Square Sandwich Panels}

A square honeycomb sandwich panel, similar to the one used in the experiment, is modeled and the results are validated through comparison with the experimental results. The sandwich panel contains vertically and horizontally aligned webs of $0.76 \mathrm{~mm}$ thickness. The front and back plates are $5 \mathrm{~mm}$ thick and the height of the hexagonal core is $51 \mathrm{~mm}$ leading to a total thickness of $61 \mathrm{~mm}$. The top surface of the honeycomb is connected through a tie-constraint to the inner surface of the top plate. A similar constraint is used to connect the bottom surface of the honeycomb to the inner surface of the bottom plate. This constraint prevents relative displacement between connected surfaces. This represents the brazing technique used to bond the webs and plates in the structure used in the experiments by Dharmasena et al. (2008). Fixed and symmetry boundary conditions are implemented in the model.

\section{Investigation of Different Square and Hexagonal Core Sizes}

Different core sizes for square and hexagonal honeycomb sandwich panels have been investigated. All dimensions are consistent with the previously mentioned experimental model, excluding the core dimensions and thickness of cell walls. Using same modeling and simulation procedures, both core shapes are compared as 
they are subjected to $1 \mathrm{~kg}, 2 \mathrm{~kg}$ and $3 \mathrm{~kg}$ of TNT. The dimensions of square and hexagonal cores are similar in terms of their Vertical Length (VL). Different vertical lengths of $15.25 \mathrm{~mm}, 30.5 \mathrm{~mm}, 61 \mathrm{~mm}, 76.25 \mathrm{~mm}$ and $152.5 \mathrm{~mm}$ have been used for both shapes. Figure 5 shows a square and a hexagonal core with vertical length of $61 \mathrm{~mm}$.

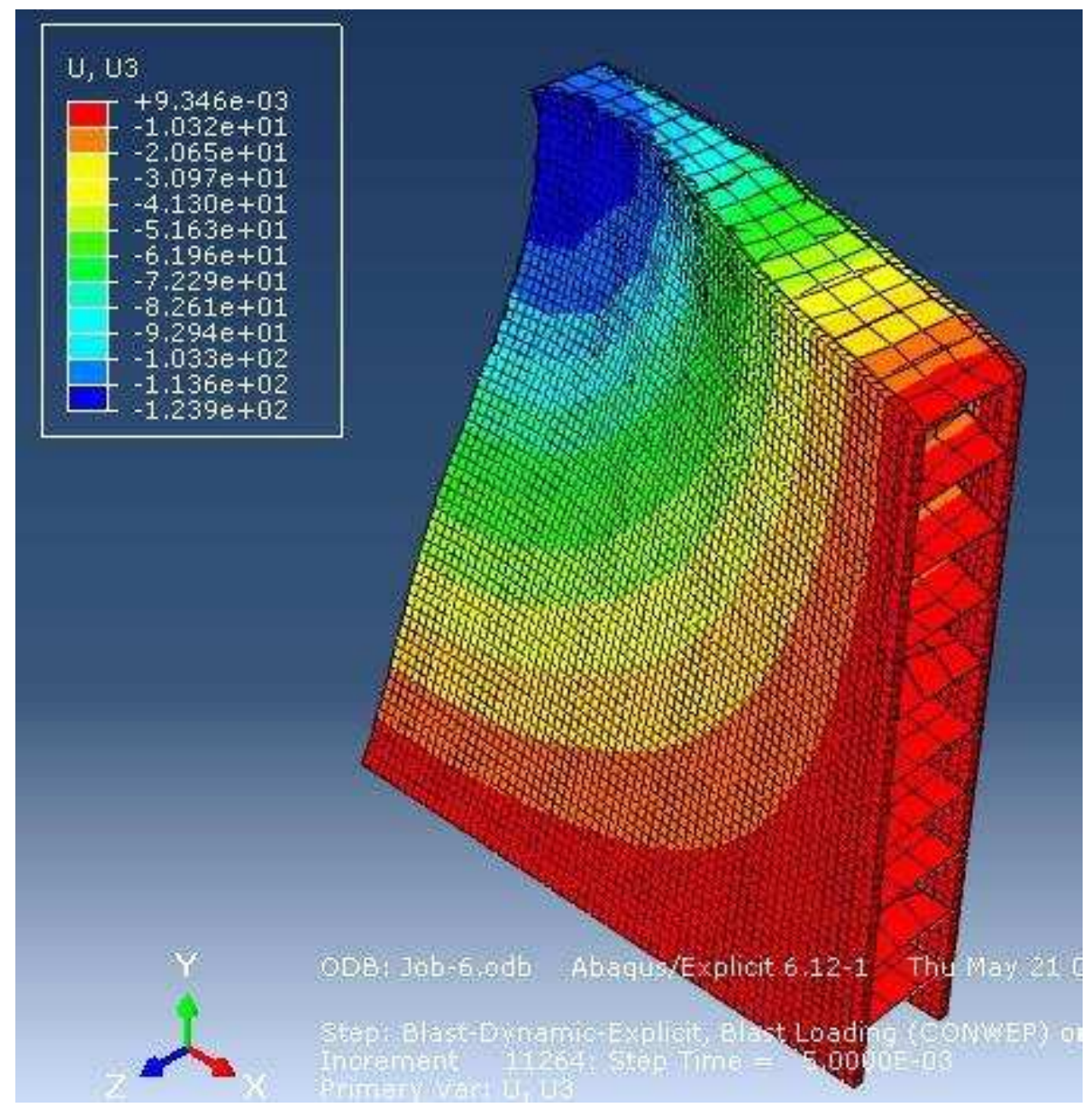

(a)

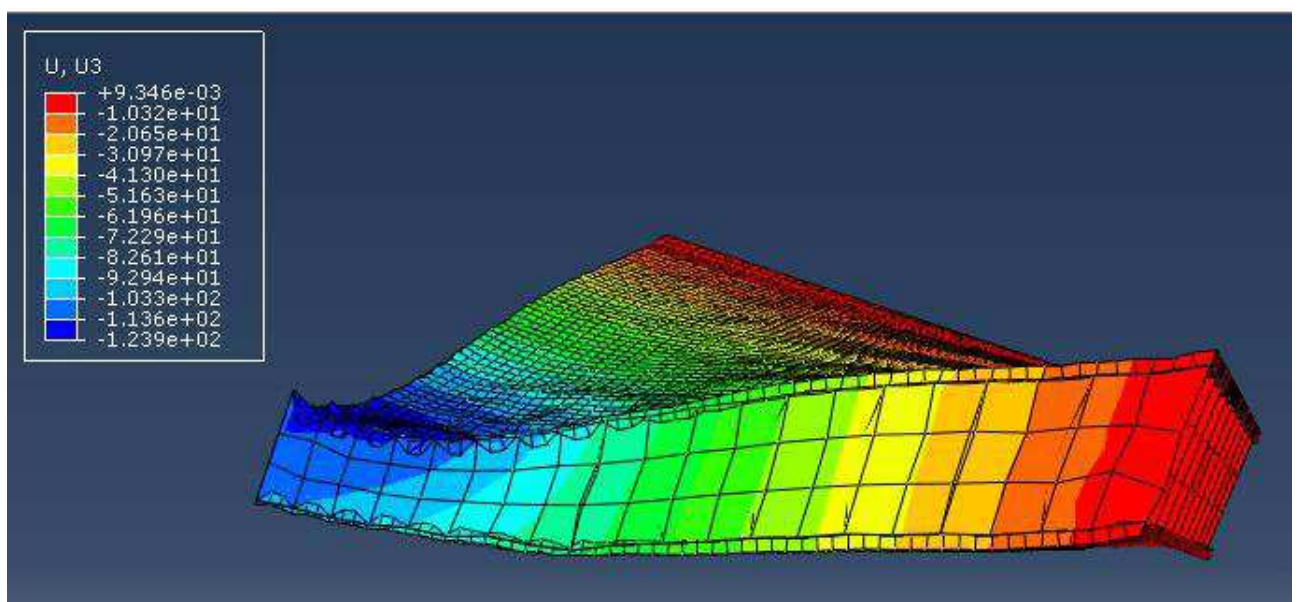

(b)

Fig. 4: Deflection of honeycomb panel (3kg of TNT): (a) front view (b) side view 


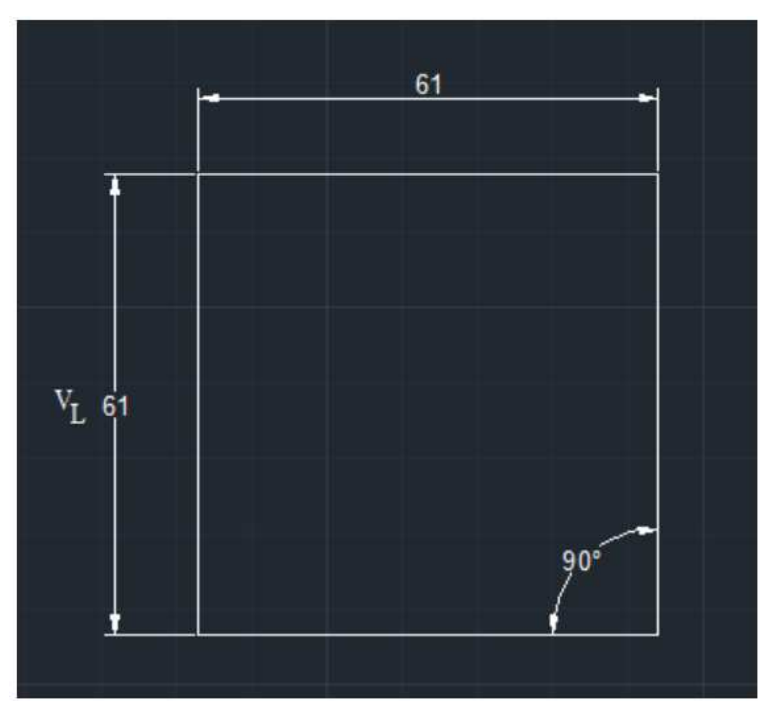

(a)

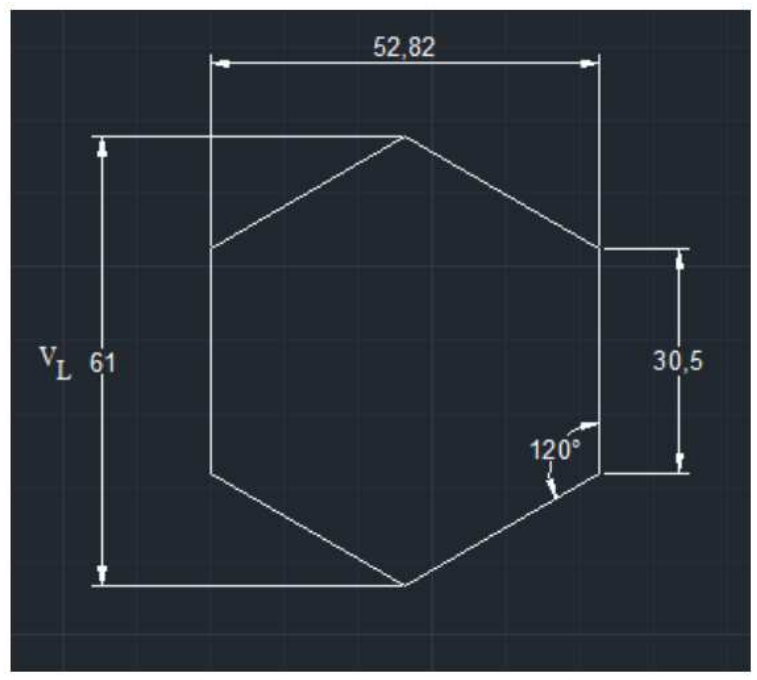

(b)

Fig. 5: Core with vertical length of $61 \mathrm{~mm}$ (a) Square core (b) Hexagonal core

\section{Optimization Study}

Plastic deformation is a process in which permanent deformation is caused by a sufficient load. It produces a permanent change in the shape or size of a solid body without fracture, resulting from the application of sustained stress beyond the elastic limit.

The equivalent plastic strain (PEEQ) is a scalar variable that is used to represent the material's plastic deformation in ABAQUS ${ }^{\circledR}$. If this value is greater than zero, the material is yielded.

The objective of the optimization process in this study is to minimize the PEEQ value of the back plate with the cell thickness as the design variable. ISIGHT $^{\circledR}$ is used in parallel with ABAQUS ${ }^{\circledR}$ for the parametric optimization. After selecting the input and output variables, together with the appropriate technique, the optimization process can be performed in ISIGHT ${ }^{\circledR}$.

Square and hexagonal honeycomb structures with a cell vertical length of $61 \mathrm{~mm}$ are selected in this optimization study. Furthermore, the optimization is performed with respect to $1 \mathrm{~kg}, 2 \mathrm{~kg}$ and $3 \mathrm{~kg}$ of TNT. The optimization problem can be defined as:

$$
\begin{aligned}
& \text { Variable }=0.5 \mathrm{~mm} \leq t \leq 5 \mathrm{~mm} \\
& \text { Objective }=\text { Minimize PEEQ }
\end{aligned}
$$

\section{Results}

The results of square honeycomb simulations are shown in Figures 6 to 8 and compared with the experimental results from Dharmasena et al. (2008).

Figures 9 to 11 show the simulation results of square and hexagonal honeycomb panels for 1,2 and $3 \mathrm{~kg}$ of TNT. Simulation results for sandwich panels with honeycomb wall thickness of $0.76 \mathrm{~mm}$ are compared in Figure 9 for different vertical lengths of the core.

Figures 10 and 11 show the simulation results for sandwich panels with honeycomb wall thickness of 1 $\mathrm{mm}$ and $1.5 \mathrm{~mm}$, respectively.

\section{Discussion}

As shown in Figures 6 to 8 , it is clear that the deformations recorded in the experiment and those from simulation are in very good agreement for the front plate of the panel for $1 \mathrm{~kg}$ and $2 \mathrm{~kg}$ of TNT. In all other cases, simulations have shown slightly different values for front and back plate deflections. This could be because the equipment and tools used in the experiment were not properly defined in the reference research paper. Another reason can be the fact that in the experimental setup, the reported displacement is the final permanent displacement, whereas in simulations the maximum displacement during the blast was reported. Comparing simulation work to the experimental work verifies the efficiency of the FEM model.

The back-plate plastic deformations versus the optimized wall thickness from the optimization process for both square and hexagonal honeycomb panels are depicted in Tables 1 and 2. Results indicate that hexagonal honeycomb panels exhibit less PEEQ plastic deformations for similar or even less wall thicknesses.

Figures 9 to 11 , also show that the shape of the cell will affect the deflection of the back plate more when the sizes are increasing. Hexagonal and square honeycomb panels demonstrate similar deflections of the back plate at the smaller vertical core lengths $(15.25 \mathrm{~mm}$ and 30.5 $\mathrm{mm}$ ), though square honeycomb panels provide better results at larger lengths $(61 \mathrm{~mm}, 76.25 \mathrm{~mm}$ and 152.5 
Sayed M. Soleimani et al. / American Journal of Engineering and Applied Sciences 2018, 11 (3): 1130.1140 DOI: 10.3844/ajeassp.2018.1130.1140

$\mathrm{mm})$. At a length of $152.5 \mathrm{~mm}$, for example, the square honeycomb exhibits $28 \%$ to $40 \%$ more reduction for back plate deflections compared to the hexagonal honeycomb.

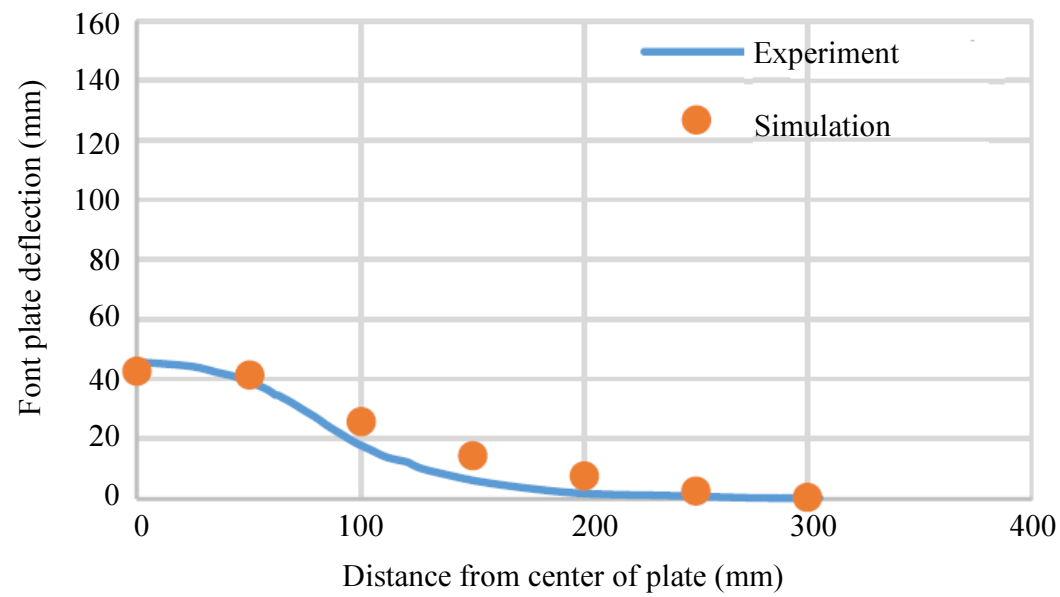

(a)

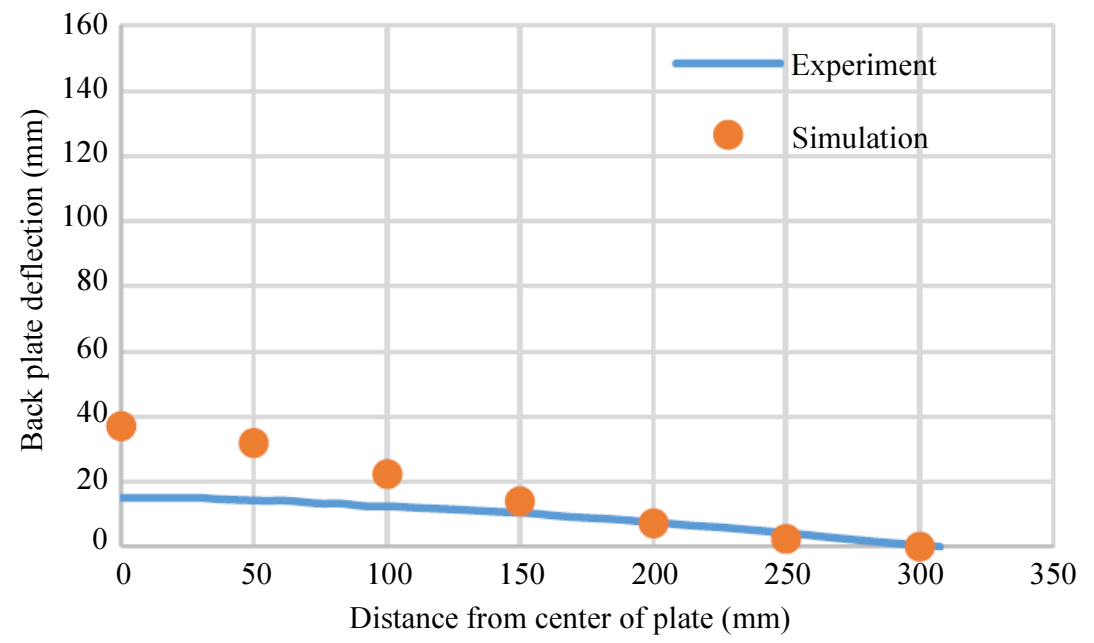

(b)

Fig. 6: Deflection Vs. Distance from the center of plate (1 kg of TNT): (a) front plate (b) back plate

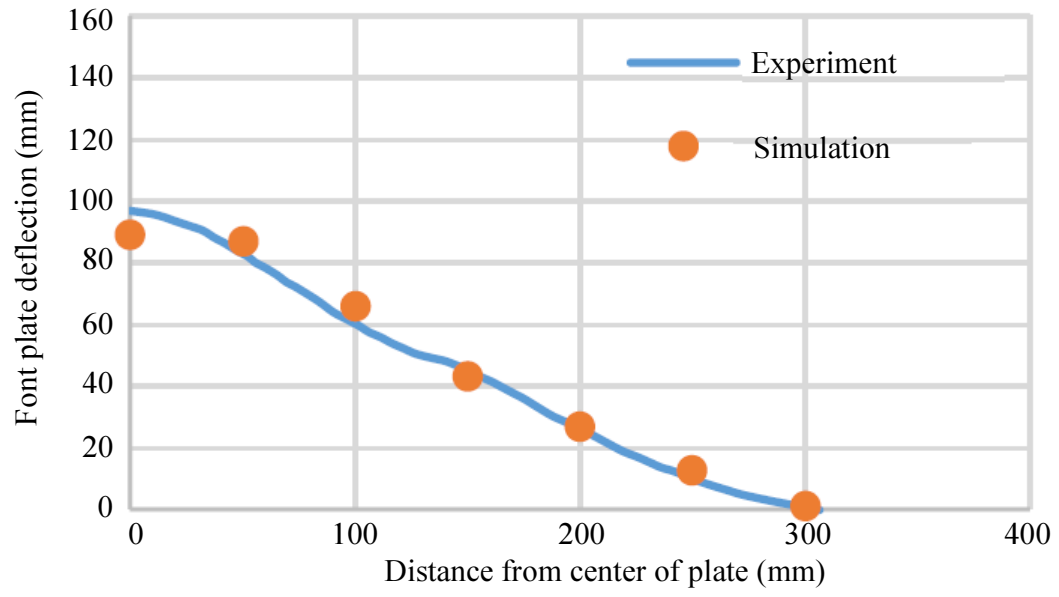

(a) 


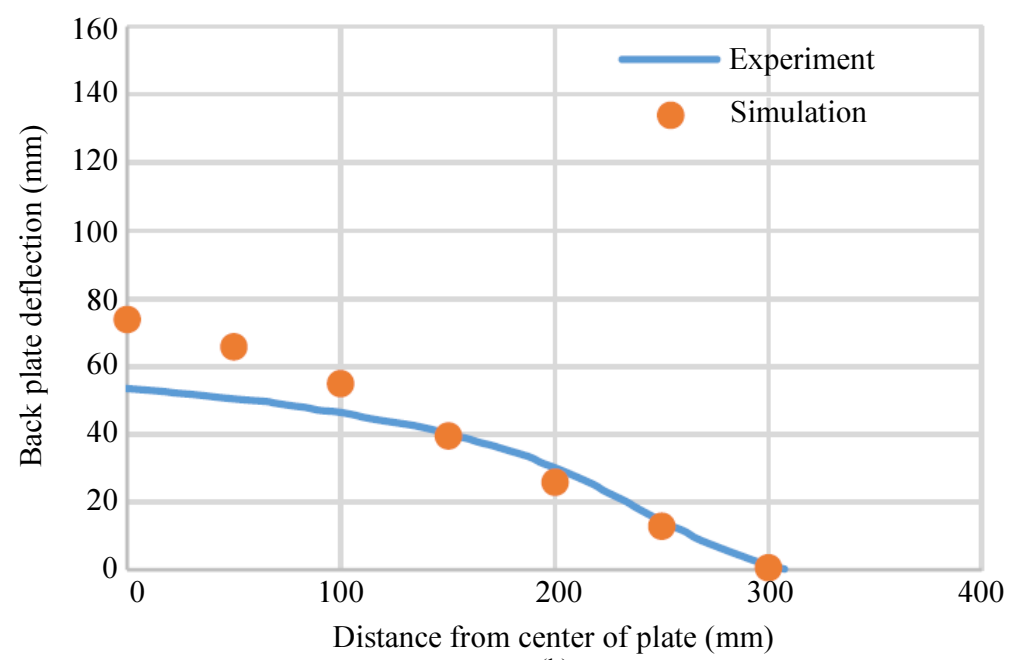

(b)

Fig. 7: Deflection Vs. distance from the center of plate (2kg of TNT): (a) front plate; (b) back plate

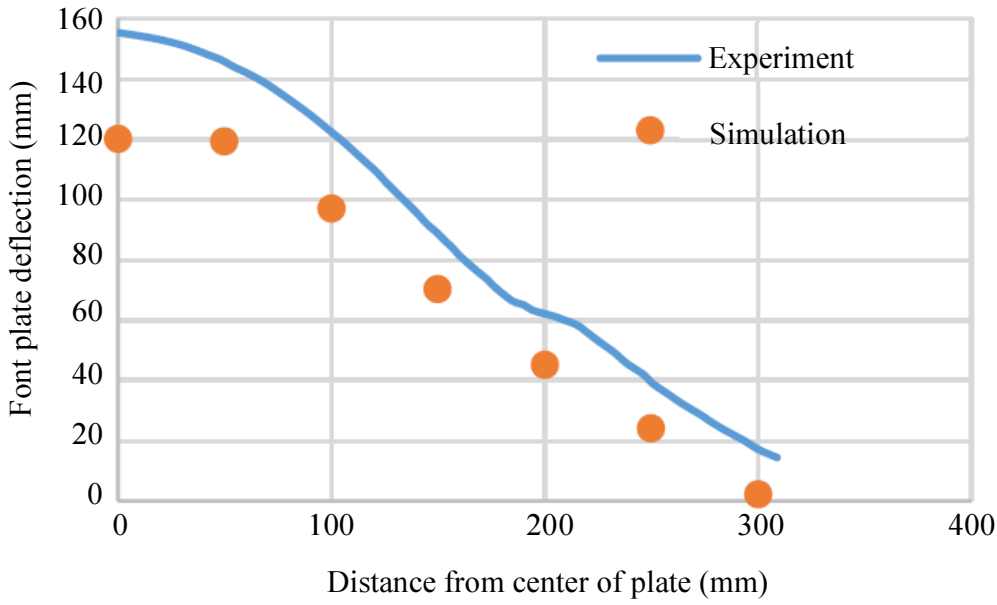

(a)

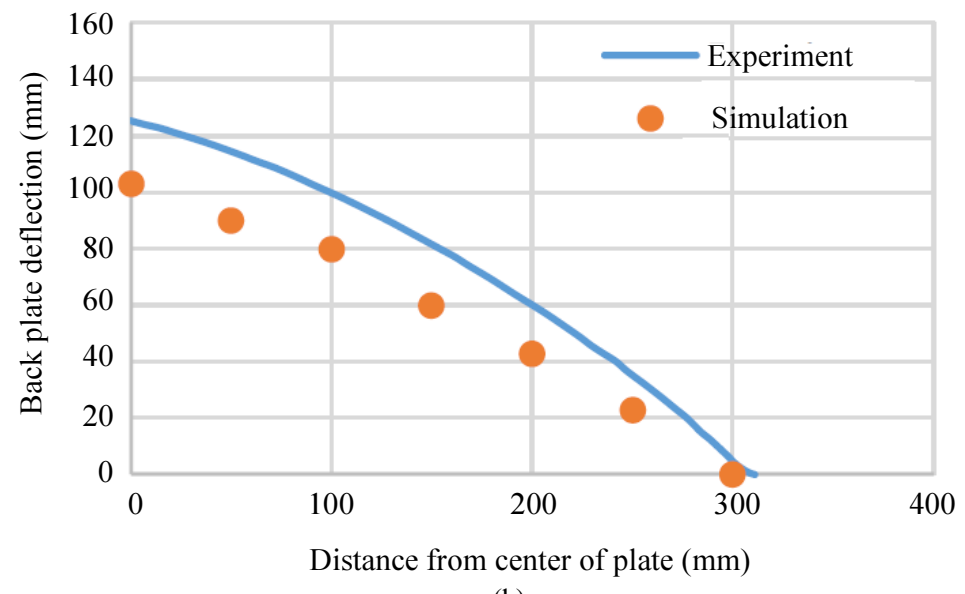

(b)

Fig. 8: Deflection Vs. Distance from the center of plate (3kg of TNT): (a) front plate; (b) back plate 


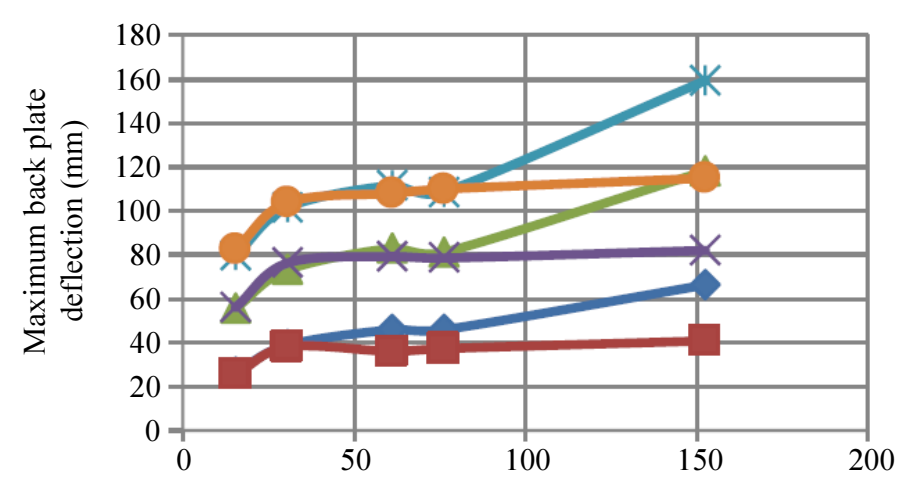

Cell length $(\mathrm{mm})$

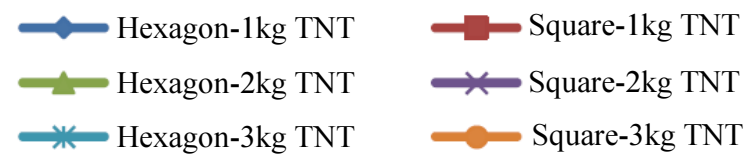

Fig. 9: Cell length Vs. maximum plate deflection of square and hexagonal sandwich panel (0.76 mm cell wall thickness)

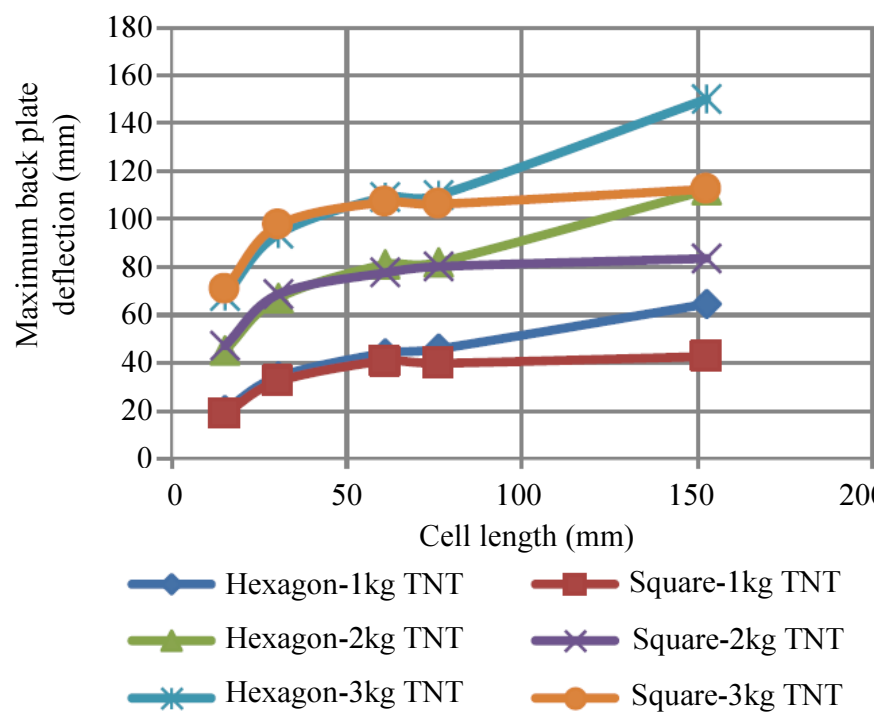

Fig. 10: Cell length Vs. maximum plate deflection of square and hexagonal sandwich panel (1 mm cell wall thickness)

Table 1: Optimization results-square honeycomb

\begin{tabular}{lll}
\hline Blast mass $(\mathrm{kg})$ & Optimized cell thickness $(\mathrm{mm})$ & PEEQ \\
\hline 1 & 4.7 & 0.039 \\
2 & 5.0 & 0.096 \\
3 & 4.9 & 0.159 \\
\hline
\end{tabular}

Table 2: Optimization results-hexagonal honeycomb

\begin{tabular}{lll}
\hline Blast mass $(\mathrm{kg})$ & Optimized cell thickness $(\mathrm{mm})$ & PEEQ \\
\hline 1 & 3.5 & 0.039 \\
2 & 5.0 & 0.099 \\
3 & 1.0 & 0.167 \\
\hline
\end{tabular}

It can be concluded from Figure 10 that the deflection of the back plate for square and hexagonal honeycomb panels are similar for vertical core lengths varying between $30.5 \mathrm{~mm}$ and $76.25 \mathrm{~mm}$. However, at a vertical core length of $152.5 \mathrm{~mm}$, the square honeycomb panel outperforms the hexagonal honeycomb panel with $25 \%$ to $35 \%$ less deflection of the back plate.

As seen in Figures 11, for all vertical core lengths except the largest one, the square and the hexagonal honeycomb panels have similar back plate deflections, whereas, at a vertical length of $152.5 \mathrm{~mm}$, the square honeycomb panel demonstrates less back plate deformation ranging between $20 \%$ to $38 \%$.

Figure 12 correlates the relative weight with the maximum deflection of the back plate. It is worth mentioning that the relative weight is referring to the ratio of the core's weight with respect to the size of the elements (i.e., if the core size is $152.5 \mathrm{~mm}$, the core weight is considered $\mathrm{W}$, this will correspond to $1.5 \mathrm{~W}$, $2.5 \mathrm{~W}, 4.5 \mathrm{~W}$ and $8.5 \mathrm{~W}$ when the core size is changed to $76.25,61,30.5$ and $15.25 \mathrm{~mm}$, respectively). 


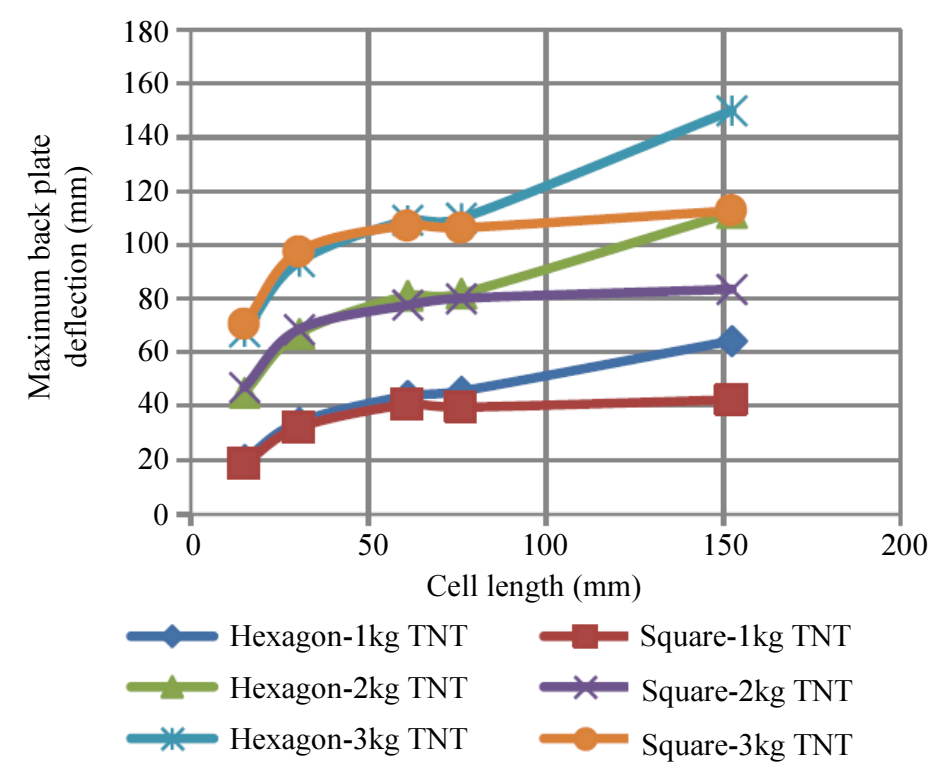

Fig. 11: Cell length Vs. maximum plate deflection of square and hexagonal sandwich panel (1.5 mm cell wall thickness)

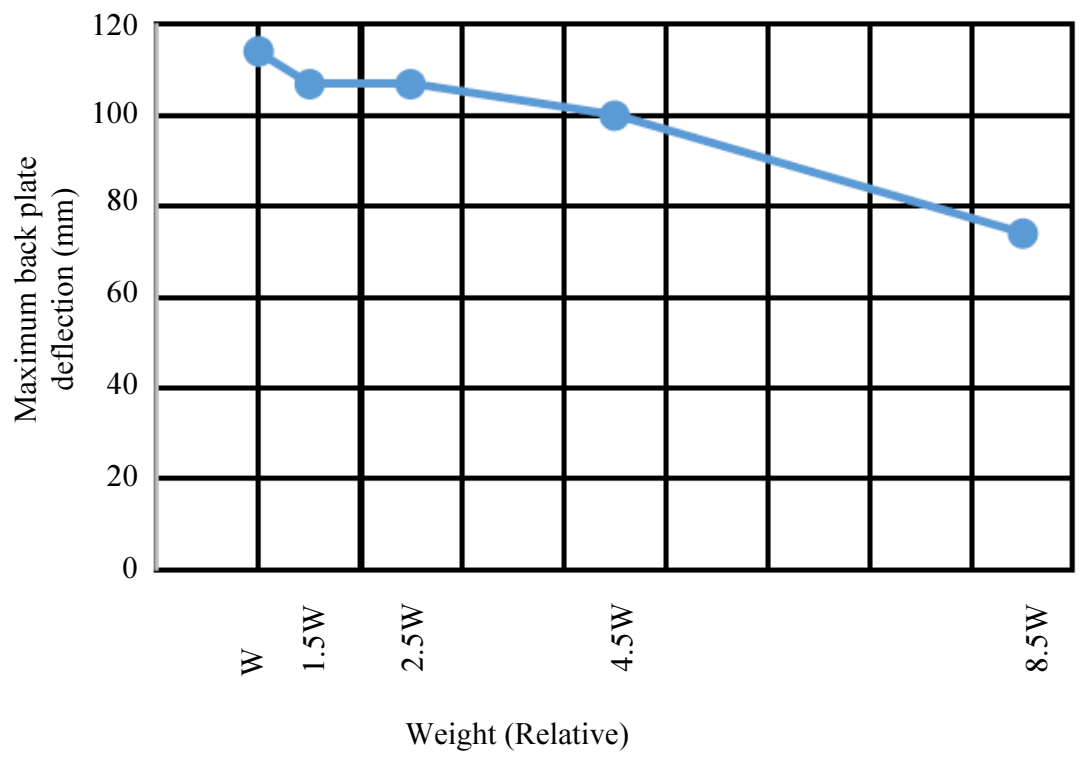

Fig. 12: Relative weight Vs. maximum plate deflection of square sandwich panel

\section{Conclusion}

In this study, it was shown that honeycomb steel sandwich panels can effectively be implemented as an appropriate means to increase the structural resistance against blast loadings. Two different configurations; square vs. hexagonal, were investigated and it was concluded that both configurations were effective. However, square core shapes were shown to be more effective as the size of the core increased. The effectiveness of core wall thickness in hexagonal and square honeycomb configurations was studied and results were presented. Moreover, the optimization study conducted in this study explored the effects of the core wall thickness on the back-plate plastic deformation. Results obtained demonstrated that the honeycomb core geometry has a significant effect on the deformation of the back plate. A more detailed optimization study with multiple design variables can help in understanding the relationship between the honeycomb core geometry and the deformation of the back plate. 


\section{Acknowledgment}

The authors would like to thank technical support of former undergraduate students of Australian College of Kuwait: Mewael D. Isiet and Muhammad B. Siddiqui.

\section{Author's Contributions}

Sayed Mohamad Soleimani and Nader Ghareeb: Guided the research and participated in writing the manuscript.

Nourhan Shaker: Performed the finite element analysis and participated in writing the manuscript.

\section{Ethics}

This article is an original research paper. There are no ethical issues that may arise after the publication of this manuscript.

\section{References}

Dharmasena, K.P., H.N.G. Wadley, Z. Xue and J.W. Hutchinson, 2008. Mechanical response of metallic honeycomb sandwich panel structures to highintensity dynamic loading. Int. J. Impact Eng., 35: 1063-1074.

DOI: 10.1016/j.ijimpeng.2007.06.008

Fleck, N.A. and V.S. Deshpande, 2004. The resistance of clamped sandwich beams to shock loading. J. Applied Mech., 71: 386-401.

DOI: $10.1115 / 1.1629109$
Nahshon, K., M.G. Pontin, A.G. Evans, J.W. Hutchinson and F.W. Zok, 2007. Dynamic shear rupture of steel plates. J. Mech. Mat. Struct., 2: 2049-2066.

DOI: 10.2140/jomms.2007.2.2049

Nayak, S.K., A.K. Singh, A.D. Belegundu and C.F. Yen, 2012. Process for design optimization of honeycomb core sandwich panels for blast load mitigation. Army Res. Laboratory, 47: 749-763.

Soleimani, S.M., N.H. Ghareeb, N.H. Shaker and M.B. Siddiqui, 2016. Modeling and simulation of honeycomb steel sandwich panels under blast loading. Proceedings of the 18th International Conference on Materials and Structural Integrity, (MSI' 16), Vancouver, BC, Canada.

Xue, Z. and J. Hutchinson, 2005. Crush dynamics of square honeycomb sandwich cores. Int. J. Numer. Meth. Eng., 65: 2221-2245. DOI: 10.1002/nme.1535

Yuen, S.C.K., G.N. Nurick, M.D. Theobald and G.S. Langdon, 2009. Sandwich Panels Subjected to Blast Loading. In: Dynamic Failure of Materials and Structures, Shukla, A., G. Ravichandran and Y. Rajapakse (Eds.), Springer, Boston, pp: 297-325.

Zhu, F. and G. Lu, 2007. A review of blast and impact of metallic and sandwich structures. Electronic $\mathrm{J}$. Struct. Eng., 7: 92-101. 